\title{
Increasing private delivery of publicly funded services?
}

Two years after Canada's political leaders signed the First Ministers' Accord on Health Care Renewal, provincial and federal governments seem more out of step with each other than ever on the question of what constitutes a legitimate role for the private sector in publicly funded health care.

But there is little doubt that there is an increasing amount of private delivery of publicly funded services — with or without consensus on whether this is appropriate.

"New examples come to light almost weekly," says Stan Marshall, a senior researcher with CUPE, the union representing more health care workers than any other labour group in Canada.

Although there is no central organization maintaining a list of private clinics or hospitals that may receive public business, unions representing health care workers estimate there are between 50 and 60 such facilities in the country. They provide services such as hernia operations, diagnostic imaging, and orthopaedic, cataract and other surgeries.

St. Paul's Hospital in Vancouver announced in November it would contract out 1000 elective surgeries to 3 private clinics in response to a shortage of operating room nurses. Those contracts expire at the end of March, but with no end to the nursing shortage in sight, already there are suggestions they will have to be extended. The practice is already widespread in $\mathrm{BC}$, where 4 out of 5 health regions contract out day surgeries to clear hospital backlogs.

In Alberta, the Calgary Regional Health Authority is sending some 500 knee and hip surgery patients over the next 2 years to a private clinic, the Health Resource Centre.

"Those surgeries will cost $10 \%$ more, and the health authority knows that," says CUPE's Marshall. "But they're doing it anyway, using the rationale of long waiting lists."

CUPE is but one of a host of labour and health groups, including the Council of Canadians and the Canadian Health Coalition, demanding Canada's political leaders make a clear commitment to the public delivery of health care services, arguing that is a prerequisite to sustaining the public health care system. An April 2004 poll by Ipsos-Reid, sponsored by CUPE and the Council of Canadians, indicated that $64 \%$ of Canadians agree that "Canada's health care system should exclue corporations that operate for-profit, and instead rely solely on public and not-forprofit health care providers."

In Ontario, that pressure has worked. The Liberal government has begun converting the private MRI clinics that sprang up under the former Conservative government to nonprofit entities, compensating the owners. That's raised the ire of Senator Michael Kirby, the chair of the Senate committee on health care.

"All they did was change the clinics' tax structure in a way that had zero impact on the people that owned them," he argues. "Yet it gets publicized as some big improvement in the system. That is, truly and frankly, deliberately misleading the public."

Kirby calls it a "great myth of Canadian public life" that the Canada Health Act prohibits private delivery of health services. "There has never been a piece of federal legislation that says who can deliver service. The rule has been those services must be publicly financed, but anybody could deliver — as long as you were not extra-billing."

That view is reiterated by Don $\mathrm{McNaught,} \mathrm{a} \mathrm{retired} \mathrm{federal}$ bureaucrat who served for many years as the director of health insurance - and who, in the mid1980s, was one of the architects of the historic Health Act.

"We've had private clinics providing medically necessary, publicly insured services from the start," McNaught says. The Shouldice Hernia Centre in Thornhill, Ont., is the bestknown example. "The Shouldice clinic was a listed facility under the old cost-sharing agreements in the 1950s. It was there in the beginning, and it's still there."

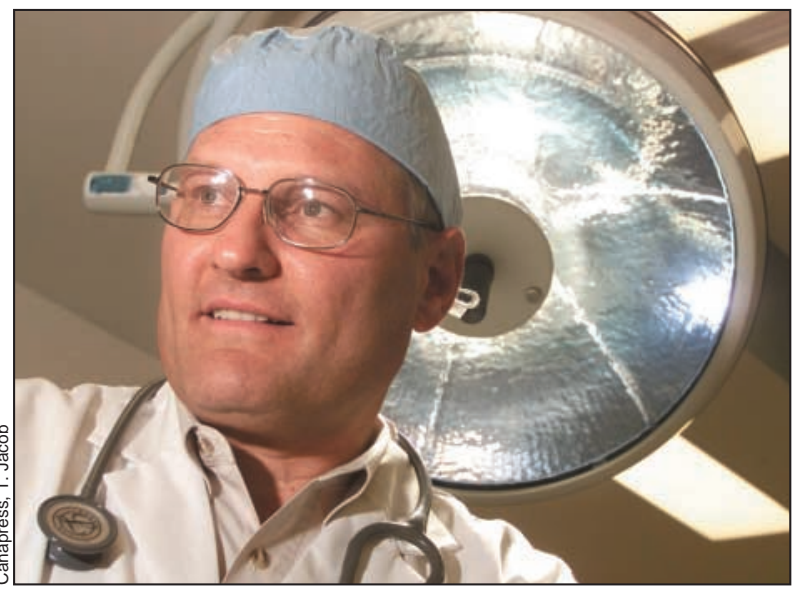

Private care, public payment: Dr. Stephen Miller at the Health Resource Centre in Calgary, which critics say is the country's first private hospital. The Calgary Regional Health Authority is sending some $\mathbf{5 0 0}$ knee and hip surgery patients over the next 2 years to the private facility.

In McNaught's view, the debate over the role of private clinics is now being driven entirely by ideology and not by the business case of whether it is, indeed, more or less costly for the public sector or the private sector to delivery health services.

"The fact is, there is no evidence private clinics are more efficient or less costly," McNaught says. Recent research (CMA7 2004;170[12]:1817-24) shows that payments for care in private for-profit hospitals in the US cost on average 19\% more than in their nonprofit counterparts. And, last May, the $B M 7$ reported that surgical services contracted out to private clinics in the UK in order to reduce waiting lists cost taxpayers, on average, $40 \%$ more. - Loreen Pindera, Montréal, Que.

Loreen Pindera is a journalist with CBC Radio in Montréal. 